\title{
Maspin suppresses growth, proliferation and invasion in cutaneous squamous cell carcinoma cells
}

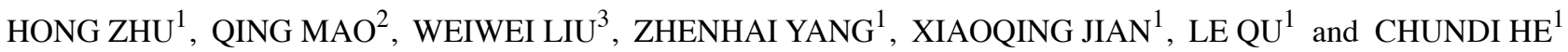 \\ ${ }^{1}$ Department of Dermatology, The First Affiliated Hospital of China Medical University, Shenyang, \\ Liaoning 110001; ${ }^{2}$ Department of Dermatology, Chengdu Fifth People's Hospital, Chengdu, Sichuan 611130; \\ ${ }^{3}$ Department of Dermatology, Chaoyang Second Hospital, Chaoyang, Liaoning 122000, P.R. China
}

Received September 27, 2016; Accepted March 7, 2017

DOI: $10.3892 /$ or.2017.5574

\begin{abstract}
Cutaneous squamous cell carcinoma (cSCC) is a common malignant tumor. Mammary serine protease inhibitor (Maspin), a member of serpin family, has been reported as a tumor suppressor in various carcinomas. In this study, we detected the expression level of Maspin in cSCC tissues by real-time PCR and western blotting, and found that Maspin was downregulated in the cSCC tissues compared with the adjacent normal tissues. Moreover, Maspin was stably overexpressed in A431 cells, and CCK-8 assay, colony formation assay, Transwell assay, Hoechst staining and western blotting were carried out to detect the growth, proliferation, invasion, cell cycle and apoptosis of A431 cells. The results revealed that overexpression of Maspin inhibited growth, proliferation, invasion and cell cycle G1/S/G2 transition and enhanced apoptosis of A431 cells. The pro-apoptotic protein cleaved caspase-3, poly(ADP-ribose) polymerase (PARP) and Bax increased, and the anti-apoptotic protein $\mathrm{Bcl}-2$ decreased after Maspin overexpression. Therefore, we demonstrated that Maspin suppressed growth, proliferation and invasion by delaying cell cycle transition and promoting apoptosis in cSCC cells, which may provide new insights for the clinical diagnosis and therapy of cSCC.
\end{abstract}

\section{Introduction}

Cutaneous squamous cell carcinoma (cSCC) is the second most common cutaneous malignant tumor, following cutaneous basal cell carcinoma (cBCC) $(1,2)$. Pathogenesis of $\mathrm{cSCC}$ is related with sun exposure, genodermatosis and immunosuppression $(3,4)$. Compared with $\mathrm{cBCC}$, cSCC shows more potential to metastasize to lymph nodes or distant organs (5),

Correspondence to: Dr Chundi He, Department of Dermatology, The First Affiliated Hospital of China Medical University, 155 North Nanjing Street, Shenyang, Liaoning 110001, P.R. China

E-mail: chundi_he2016@163.com

Key words: Maspin, cutaneous squamous cell carcinoma, growth, proliferation, invasion and 5-year survival rate of the patients with local metastasis is $<30 \%(6,7)$. Currently, the main treatment is surgery, supplemented with radiotherapy and/or chemotherapy, however, this may leave serious sequelae (8). Therefore, it is of important clinical significance to study the pathogenesis of cSCC and to develop more effective diagnoses and treatments.

Mammary serine protease inhibitor (Maspin) belongs to serpin family, and its encoding gene is located in 18q21 in Homo sapiens (9). Since the subtle differences between Maspin and other members of serpin family in secondary structure, there is no protease inhibited by Maspin via the classical serpin pathway to date (10-13). Initially Maspin is expressed in human mammary epithelial tissue and breast carcinoma tissue with an antitumor function (14). Subsequently, a large number of studies reported that Maspin was expressed in multiple normal tissues, including breast, prostate, placenta and epidermal keratinocytes, while downregulated or could not be detected in various cancers. Maspin inhibits epidermal growth factor (EGF)-induced epithelial-mesenchymal transition (EMT) of esophageal carcinoma cells, suppresses proliferation in soft agar, migration and invasion, even induces transition of tumor cells into benign cells (15). Maspin inhibits vasculogenic mimicry in non-small cell lung cancer (NSCLC) cells, and its expression level is positively correlated with prognostic implication in NSCLC patients (16). Maspin promotes tumor cells apoptosis in breast and prostate cancer $(17,18)$. Maspin suppresses prostate tumor growth, invasion and metastasis by inhibiting histone deacetylization, and activates host neutrophil- and B cell-dependent antitumor immune response (19). Therefore, Maspin could be an effective marker for diagnosis and therapy of cancers. Recently, some reports found that Maspin is expressed in detected normal skin tissue, but partly expressed in cSCC and cBCC $(20,21)$, and the expression level of Maspin is positively correlated with prognosis of cSCC patients (16), suggesting that Maspin may participate in cSCC progress. However, the role of Maspin in cSCC carcinogenesis and development is not clear.

In this study, we examined the expression level of Maspin in cSCC tissue, and found that it was obviously downregulated compared with normal cutaneous tissues. Subsequently, by establishing Maspin stably expressed cell line, we demonstrated that Maspin inhibited growth, proliferation, invasion by delaying cell cycle transition and enhancing apoptosis in 
cSCC cells. These findings may provide new insights into carcinogenesis, diagnosis and therapy of cSCC.

\section{Materials and methods}

Human tissue specimens. Seventeen pairs of clinical cSCC samples were collected from cSCC patients operated from September 2012 to April 2015 in Department of Dermatology, The First Affiliated Hospital of China Medical University. Each sample pair contains a cSCC tissue, an adjacent tissue $0.5 \mathrm{~cm}$ from cSCC tissue and an adjacent tissue $1 \mathrm{~cm}$ from cSCC tissue. The patients had not been treated with radiotherapy or chemotherapy. Informed consent was obtained from the patients, and our collection and treatment procedures were in line with standards of the ethics committee of The First Affiliated Hospital of China Medical University.

RNA extraction, reverse transcription and real-time PCR. The total RNA was extracted by total RNA rapid extraction kit (BioTeke, Beijing, China) from tissues or cells, and detailed procedure referred to the manufacturer's protocol. The obtained RNA samples were reverse transcribed into cDNA by Super M-MLV reverse transcriptase (BioTeke), with the oligo(dT) and random primers. All instruments in this section were treated by RNase Erasol (Tiandz, Beijing, China), and all reagents were RNase-free.

The cDNA was used to perform real-time PCR with $2 \mathrm{X}$ power Taq PCR MasterMix (BioTeke) and SYBR Green (Solarbio, Beijing, China) to test Maspin mRNA level, with $\beta$-actin as the internal control. The PCR procedure was set as follows: $95^{\circ} \mathrm{C}$ for $10 \mathrm{~min}, 40$ cycles of $95^{\circ} \mathrm{C}$ for $10 \mathrm{sec}, 60^{\circ} \mathrm{C}$ for $20 \mathrm{sec}$ and $72^{\circ} \mathrm{C}$ for $30 \mathrm{sec}$, and finally $4^{\circ} \mathrm{C}$ for $5 \mathrm{~min}$. The data were analyzed by Exicycler ${ }^{\mathrm{TM}} 96$ (Bioneer, Daejeon, Korea), calculated by $2^{-\Delta \Delta \mathrm{Ct}}$ method (cells) or $2^{-\mathrm{ACt}}$ method (tissues) (22). Sequences of real-time PCR primers (Sangon, Shanghai, China) are shown in Table I.

Western blotting. The total protein was extracted from cells or tissues with RIPA lysis buffer (Beyotime, Haimen, Jiangsu, China). After measuring the concentration, the protein sample was denatured by boiling, separated by SDS-PAGE (density of gel dependent on the protein size), and transferred onto polyvinylidene fluoride (PVDF) membranes (Millipore, Boston, MA, USA). After blocking with 5\% skim milk (YILI, Hohhot, Inner Mongolia, China) for $1 \mathrm{~h}$, the PVDF membrane was incubated with the following antibodies at $4^{\circ} \mathrm{C}$ overnight: polyclonal rabbit anti-Maspin (Abcam, Cambrige, UK) $(1: 1,000)$, polyclonal rabbit anti-cleaved caspase-3 (Abcam) $(1: 1,000)$, monoclonal rabbit anti-cleaved poly(ADP-ribose) polymerase (PARP) (Abcam) (1:1,000), polyclonal rabbit anti-Bcl-2 (Boster, Wuhan, Hubei, China) (1:400), and polyclonal rabbit anti-Bax (Boster) (1:400). After rinsing with TBST, the PVDF membrane was incubated with goat anti-rabbit IgG-HRP (Beyotime) $(1: 5,000)$ at room temperature for $45 \mathrm{~min}$, and exposed with ECL reagent (7 sea, Shanghai, China). After antibodies were removed by stripping buffer (Beyotime), the PVDF membrane was incubated with monoclonal mouse anti$\beta$-actin (Santa Cruz, CA, USA) $(1: 1,000)$ and goat anti-mouse IgG-HRP (Beyotime) $(1: 5,000)$ to test the internal control, $\beta$-actin.
Plasmid construction. To construct Maspin overexpression plasmid, Maspin coding sequence (CDS) was obtained by PCR from human cDNA, and amplified by TA cloning using UltraPower pUM-T rapid cloning kit (BioTeke). After sequencing, the Maspin CDS fragment was inserted into pcDNA3.1 vector (XhoI+HindIII), and the overexpression plasmid pcDNA3.1-Maspin was gained. The sequences of PCR primers are shown in Table II.

Cell culture, transfection and monoclonal cell line. Three cSCC cell lines A431, SCL-1 and SCC12, were preserved in our laboratory. A431 cells and SCL-1 cells were cultured in DMEM (Hyclone, Logan, UT, USA) supplemented with $10 \%$ fetal bovine serum (FBS) (Hyclone) (SCC12 cells with $20 \% \mathrm{FBS}), 100 \mathrm{U} / \mathrm{ml}$ penicillin, $100 \mu \mathrm{g} / \mathrm{ml}$ streptomycin (Beyotime) at $37^{\circ} \mathrm{C}$ incubator (Lishen, Tianjin, China) with $5 \% \mathrm{CO}_{2}$. The overexpression plasmid pcDNA3.1-Maspin and the control pcDNA3.1 were transfected into A431 cells by Lipofectamine 2000 Reagent (Invitrogen, Carlsbad, CA, USA) with serum-free medium, 24 h later, G418 (Invitrogen) was added into medium with $100 \mu \mathrm{g} / \mathrm{ml}$ to screen the integrated cells, and the medium was refreshed every 2-3 days until the monoclonal cell lines were obtained.

CCK-8 assay. Cell counting kit-8 (CCK-8) assay was performed to test the cell viability. A431 cells were seeded into 96 -well plates with $3 \times 10^{3}$ per pore beforehand. After cells adhered, CCK-8 reagent (Beyotime) was added into the 96-well plate with $10 \mu \mathrm{l}$ per pore to incubate for $1 \mathrm{~h}$, and the optical density of the solution was tested at $450 \mathrm{~nm}$ with a microplate reader (BioTek, VT, USA). This $\mathrm{OD}_{450}$ value was the datum at $0 \mathrm{~h}$, and the data in $24 \mathrm{~h}, 48 \mathrm{~h}, 72 \mathrm{~h}$ and $96 \mathrm{~h}$ were detected later, respectively.

Colony formation assay. Colony formation assay was performed to detect the colony formation ability of A431 cells. A431 cells were seeded into a $35-\mathrm{mm}$ petri dish at 400/well, and cultured in $5 \% \mathrm{CO}_{2}$ at $37^{\circ} \mathrm{C}$, medium was refreshed every 3 days. Approximately 14 days later, most of the clones had formed. The cells were fixed with $4 \%$ paraformaldehyde (Sinopharm, Beijing, China) for $20 \mathrm{~min}$, stained with WringsGiemsa stain (Jiancheng, Nanjing, Jiangsu, China) for 5-8 min, and the clone number was counted with an inverted phase contrast microscope (Motic, Xiamen, Fujian, China). The clones with $\geq 50$ cells were considered positive.

In vitro Transwell assay. To measure the invasion potential of A431 cells, the Transwell assay in the presence of Matrigel (BD, Franklin Lakers, NJ, USA) was performed in Transwell chambers with $8-\mu \mathrm{m}$ aperture polycarbonate membrane (Corning, NY, USA). Beforehand $40 \mu \mathrm{l}$ of $2.5 \mathrm{mg} / \mathrm{ml}$ Matrigel was added into Transwell upper chamber to coat the polycarbonate membrane, and preheated at $37^{\circ} \mathrm{C}$ for $2 \mathrm{~h}$ to solidify. Then $200 \mu \mathrm{m}$ serum-free cell suspension $\left(2 \times 10^{4}\right.$ cells $)$ were added into Transwell upper chamber, and $800 \mu \mathrm{m}$ DMEM with $20 \%$ FBS was added in the lower chamber. After culturing for $24 \mathrm{~h}$, the Transwell chamber was fixed in $4 \%$ paraformaldehyde (Sinopharm) for $20 \mathrm{~min}$, and stained by $0.5 \%$ crystal violet for $5 \mathrm{~min}$. Then the cells in upper chamber were wiped off, and the cells on reverse side of polycarbonate membrane 
Table I. The real-time PCR data in 17 pairs of clinical cutaneous squamous cell carcinoma samples.

\begin{tabular}{|c|c|c|c|c|c|}
\hline Sample no. & $2^{-\Delta \mathrm{Ct}}$ mean & Sample no. & $2^{-\Delta \mathrm{Ct}}$ mean & Sample no. & $2^{-\Delta \mathrm{Ct}}$ mean \\
\hline $1 \mathrm{~A}$ & 0.000598 & $1 \mathrm{~B}$ & 0.000448 & $1 \mathrm{C}$ & 0.000799 \\
\hline $2 \mathrm{~A}$ & 0.001075 & $2 \mathrm{~B}$ & 0.000848 & $2 \mathrm{C}$ & 0.001307 \\
\hline $3 \mathrm{~A}$ & 0.000963 & $3 \mathrm{~B}$ & 0.000776 & $3 \mathrm{C}$ & 0.001453 \\
\hline $4 \mathrm{~A}$ & 0.002595 & $4 B$ & 0.002737 & $4 \mathrm{C}$ & 0.004600 \\
\hline $5 \mathrm{~A}$ & 0.000446 & $5 \mathrm{~B}$ & 0.000537 & $5 \mathrm{C}$ & 0.000865 \\
\hline $6 \mathrm{~A}$ & 0.001572 & $6 \mathrm{~B}$ & 0.001942 & $6 \mathrm{C}$ & 0.002049 \\
\hline $7 \mathrm{~A}$ & 0.002300 & $7 \mathrm{~B}$ & 0.002198 & $7 \mathrm{C}$ & 0.002537 \\
\hline $8 \mathrm{~A}$ & 0.002489 & $8 \mathrm{~B}$ & 0.004308 & $8 \mathrm{C}$ & 0.006680 \\
\hline $9 \mathrm{~A}$ & 0.000755 & $9 B$ & 0.000957 & $9 \mathrm{C}$ & 0.001874 \\
\hline $10 \mathrm{~A}$ & 0.000842 & $10 \mathrm{~B}$ & 0.001102 & $10 \mathrm{C}$ & 0.001078 \\
\hline $11 \mathrm{~A}$ & 0.003457 & $11 \mathrm{~B}$ & 0.003549 & $11 \mathrm{C}$ & 0.009217 \\
\hline $12 \mathrm{~A}$ & 0.001512 & $12 \mathrm{~B}$ & 0.001421 & $12 \mathrm{C}$ & 0.002616 \\
\hline $13 \mathrm{~A}$ & 0.000944 & 13B & 0.001162 & $13 \mathrm{C}$ & 0.003862 \\
\hline $14 \mathrm{~A}$ & 0.001632 & $14 \mathrm{~B}$ & 0.002303 & $14 \mathrm{C}$ & 0.006408 \\
\hline $15 \mathrm{~A}$ & 0.000317 & $15 \mathrm{~B}$ & 0.000313 & $15 \mathrm{C}$ & 0.000820 \\
\hline $16 \mathrm{~A}$ & 0.000431 & $16 \mathrm{~B}$ & 0.001106 & $16 \mathrm{C}$ & 0.001471 \\
\hline $17 \mathrm{~A}$ & 0.000451 & 17B & 0.000665 & $17 \mathrm{C}$ & 0.001570 \\
\hline
\end{tabular}

Each sample pair contains three samples, A represents the cutaneous squamous cell carcinoma (cSCC) tissue, B represents the adjancent tissue $0.5 \mathrm{~cm}$ from cSCC tissue, and $\mathrm{C}$ represents the adjacent tissue $1 \mathrm{~cm}$ from $\mathrm{cSCC}$ tissue. The mRNA of each tissue was tested in triplicate by real-time PCR, the data were analyzed by $2^{-\Delta \mathrm{Ct}}$ method, with respective $\beta$-actin as the internal control. The mean of data in each tissue was calculated by Excel software.

Table II. Sequences of primers used in this study.

\begin{tabular}{ll}
\hline Name & \multicolumn{1}{c}{ Sequence (5'-3') } \\
\hline Maspin F & 5'-TTGTGGTTAATGCTGCCTAC-3' \\
Maspin R & 5'-CCAAGCCTGTGGACTCATC-3' \\
$\beta$-actin F & 5'-CTTAGTTGCGTTACACCCTTTCTTG-3' \\
$\beta$-actin R & 5'-CTGTCACCTTCACCGTTCCAGTTT-3' \\
Maspin-CDS F & 5'-CTCAAAGCTTATGGATGCCCTGCAACTA-3' \\
Maspin-CDS R & 5'-CGACCTCGAGCACTTAAGGAGAACAGAAT-3' \\
\hline
\end{tabular}

Maspin, mammary serine protease inhibitor; F, forward; R, reverse; CDS, coding sequence.

were counted with an inverted phase contrast microscope (Motic) at x200 magnification.

Hoechst staining. In order to observe the nuclear morphology change, Hoechst staining was performed. A431 cells were seeded onto glass slides in 12 -well plates with $1 \times 10^{5} /$ pore. When the confluence reached $80 \%$, the cells were treated with Hoechst Staining kit (Beyotime), observed with a fluorescence microscope (Olympus, Tokyo, Japan) at x400 magnification.

Flow cytometry. Flow cytometry was performed to test apoptosis and cell cycle of A431 cells. A431 cells cultured in 6-well plates were collected when the confluence reached $90 \%$. After rinsing with PBS (Double-helix, Shanghai, China) twice, the cells were treated with Annexin V-FITC/PI cell apoptosis test kit (Wanleibio, Shenyang, Liaoning, China) and detected using FACSCalibur (BD) according to the manufacturer's protocol.

For the cell cycle analysis, the collected cells were treated by Cell Cycle Analysis kit (Beyotime), and detected using FACSCalibur (BD) according to the specification. Proliferation index $(\mathrm{PI})=($ percentage of cells in $\mathrm{S}$ phase $+\mathrm{G} 2 / \mathrm{M}$ phase $) /$ percentage of cells in G1 phase (23).

Statistical analysis. The data in this study are presented as mean \pm standard deviation (SD) with three individual experiments, and analyzed by one-way ANOVA test or paired Student's t-test. It was considered statistically significant at $\mathrm{P}<0.05, \mathrm{P}<0.01$, or $\mathrm{P}<0.001$; NS, not significant).

\section{Results}

Maspin is downregulated in cSCC tissues. First we detected the expression level of Maspin in 17 pairs of cSCC and adjacent tissues by real-time PCR and western blotting. As shown in Fig. 1, A, B and C groups represented the cSCC tissues, the adjacent tissues $0.5 \mathrm{~cm}$ from $\mathrm{cSCC}$ and the adjacent tissues $1 \mathrm{~cm}$ from $\mathrm{cSCC}$, respectively. The results showed that the mRNA level of Maspin in cSCC tissues decreased by $55 \%$ (Fig. 1A and Table II), and the protein level decreased by $49 \%$ compared to the adjacent tissue $1 \mathrm{~cm}$ from cSCC tissues (Fig. 1B and C), respectively.

Establishment of Maspin stably expressed cell line. Because of the low expression level of Maspin in cSCC tissues, among 
A

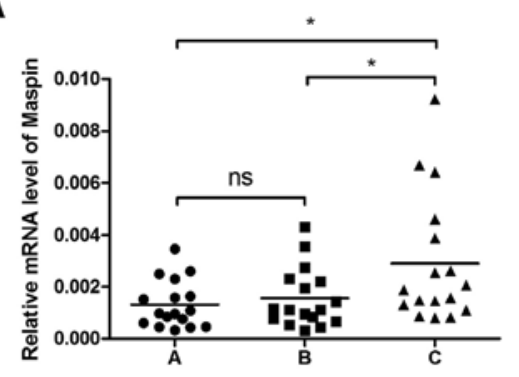

B

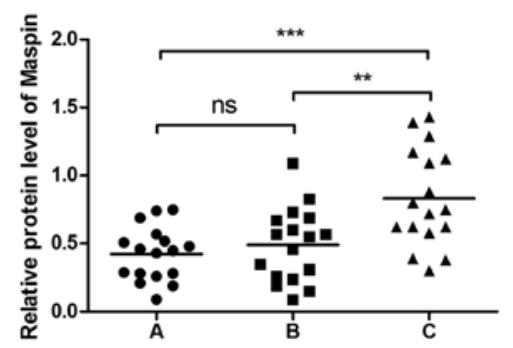

C
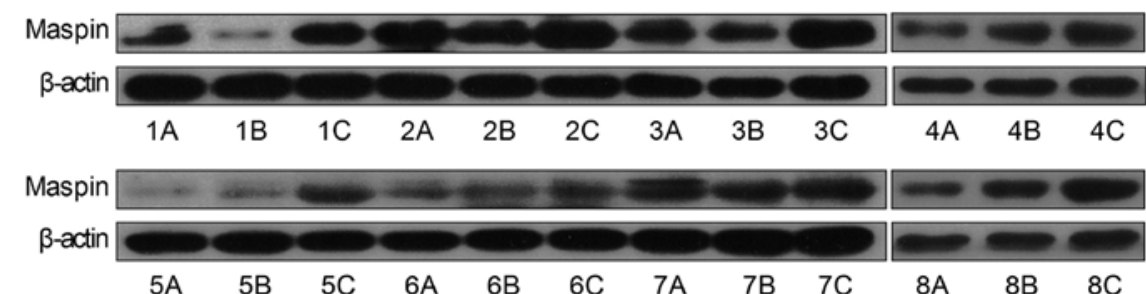

Maspin w w w =

\begin{tabular}{lllllllllll|}
\hline -actin & & & & & & & & & & \\
\hline $9 \mathrm{~A}$ & $9 \mathrm{~B}$ & $9 \mathrm{C}$ & $10 \mathrm{~A}$ & $10 \mathrm{~B}$ & $10 \mathrm{C}$ & $11 \mathrm{~A}$ & $11 \mathrm{~B}$ & $11 \mathrm{C}$
\end{tabular}

Maspin $-\infty-\infty=$

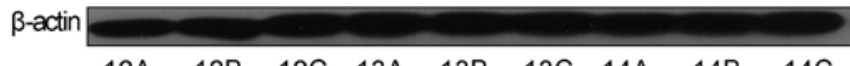

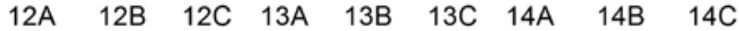

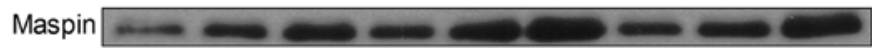

\begin{tabular}{lllllllll|}
\hline B-actin & \multicolumn{1}{|c}{10} \\
\hline $15 \mathrm{~A}$ & $15 \mathrm{~B}$ & $15 \mathrm{C}$ & $16 \mathrm{~A}$ & $16 \mathrm{~B}$ & $16 \mathrm{C}$ & $17 \mathrm{~A}$ & $17 \mathrm{~B}$ & $17 \mathrm{C}$
\end{tabular}

Figure 1. Maspin is downregulated in cSCC tissues. (A) The mRNA level of mammary serine protease inhibitor (Maspin) in cutaneous squamous cell carcinoma (cSCC) and adjacent tissues was detected by real-time PCR. (B) The protein level of Maspin in cSCC and adjacent tissues was detected by western blotting. (C) The protein bands in each tissue. A, cSCC tissues; $\mathrm{B}$, adjacent tissues $0.5 \mathrm{~cm}$ from cSCC; $\mathrm{C}$, adjacent tissues $1 \mathrm{~cm}$ from cSCC $\left({ }^{*} \mathrm{P}<0.05,{ }^{* *} \mathrm{P}<0.01\right.$, ${ }^{* * *} \mathrm{P}<0.001$; NS, not significant).

three cSCC cell lines SCL-1, SCC12 and A431, we selected A431 cells, in which the Maspin expression level was the lowest (Fig. 2A), to measure the effect of Maspin on cSCC cells. To stably express Maspin, the overexpression plasmid pcDNA3.1-Maspin was constructed, and transfected into A431 cells. By screening with G418, monoclonal cells of pcDNA3.1Maspin were obtained, and the pcDNA3.1 vector monoclonal cells were gained as the control. Real-time PCR and western blotting were performed to verify the expression efficiency of pcDNA3.1-Maspin. The results showed that the mRNA level increased by 3.78-fold (Fig. 2B), and the protein level increased by 3.86-fold (Fig. 2C) in contrast to the pcDNA3.1 group. Hence Maspin overexpression cell line was used for the subsequent experiments.

Maspin inhibits growth, proliferation and invasion in cSCC cells. CCK-8 assay, colony formation assay and Transwell assay supplemented with Matrigel in vitro were performed to detect the cell viability, colony formation ability and invasion potential of A431 cells. The results showed that A431 cell viability decreased by $22 \%, 19 \%, 20 \%$ and $22 \%$ at $24 \mathrm{~h}, 48 \mathrm{~h}$, $72 \mathrm{~h}$ and $96 \mathrm{~h}$, respectively (Fig. 3A), the colony formation rate declined by $45 \%$ (Fig. 3B), and the invasion potential descended by $39 \%$ as a result of elevation of Maspin (Fig. 3C).
Collectively, the results demonstrated that Maspin inhibited growth, proliferation and invasion in A431 cells.

Maspin delays cell cycle transition and enhances apoptosis in cSCC cells. We confirmed that Maspin expression was low in $\mathrm{cSCC}$ tissues, and inhibited growth, proliferation and invasion in cSCC cells, hence we were interested in how Maspin affects the phenotype of cSCC cells. In order to explore the underlying mechanism, we tested whether Maspin affected cell cycle transition and apoptosis in cSCC cells. Flow cytometry results showed that Maspin overexpression delayed cell cycle G1/S/G2 transition (Fig. 4A), and proliferation index (PI) decreased by $60 \%$ in A431 cells (Fig. 4B).

To detect the effect of Maspin on apoptosis of A431 cells, Hoechst staining, flow cytometry and western blotting were performed. In the Hoechst staining results, Maspin overexpressed A431 cells showed more intense fluorescence than parental and pcDNA3.1 groups (Fig. 5A), which is characteristic of apoptotic cells. Flow cytometry results showed that Maspin increased cell apoptosis rate of A431 cells 7-fold (Fig. 5B and C). In addition, we detected several apoptosis related genes. As shown in Fig. 5, cleaved caspase-3 increased 2-fold, cleaved PARP was upregulated 2.5-fold, Bcl-2 descended by $48 \%$, and Bax was elevated 1.6-fold (Fig. 5D 

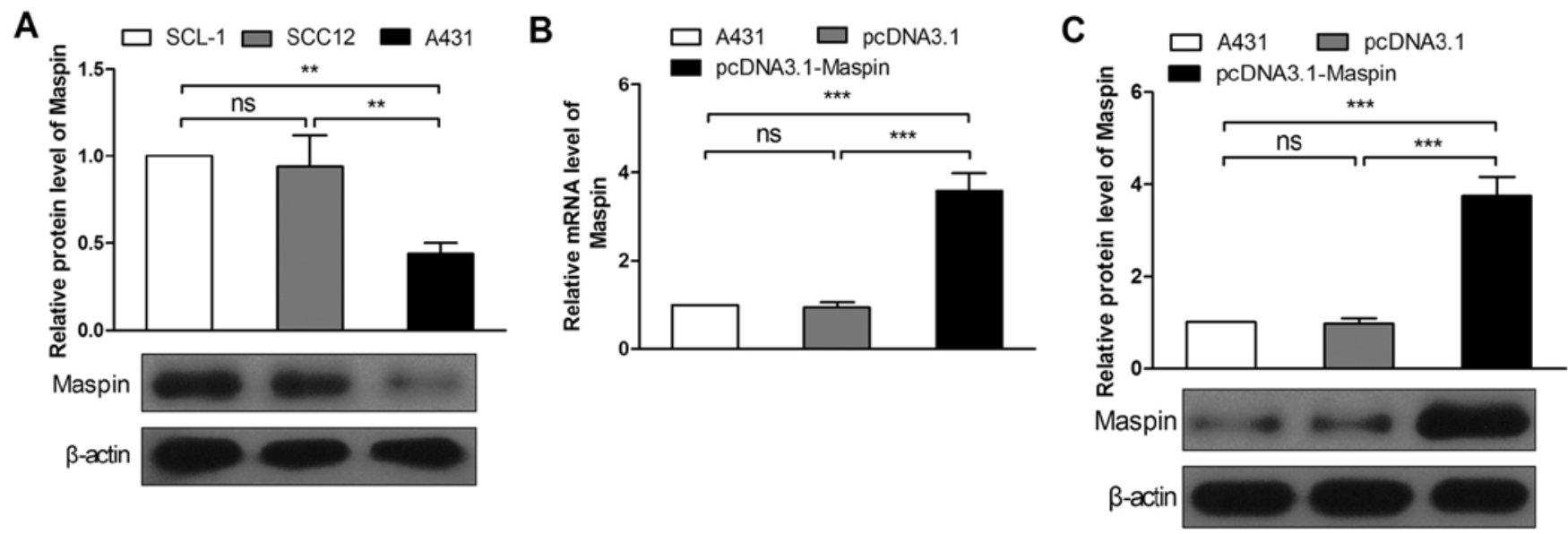

Figure 2. Establishment of Maspin stably expressed cell line. (A) The expression level of Maspin in SCL-1 cells, SCC12 cells and A431 cells detected by western blotting. (B and C) Real-time PCR and western blotting were used to confirm the expression efficiency of pcDNA3.1-Maspin in A431 cells ("*P $<0.01$, ${ }^{* * *} \mathrm{P}<0.001 ; \mathrm{NS}$, not significant).

A
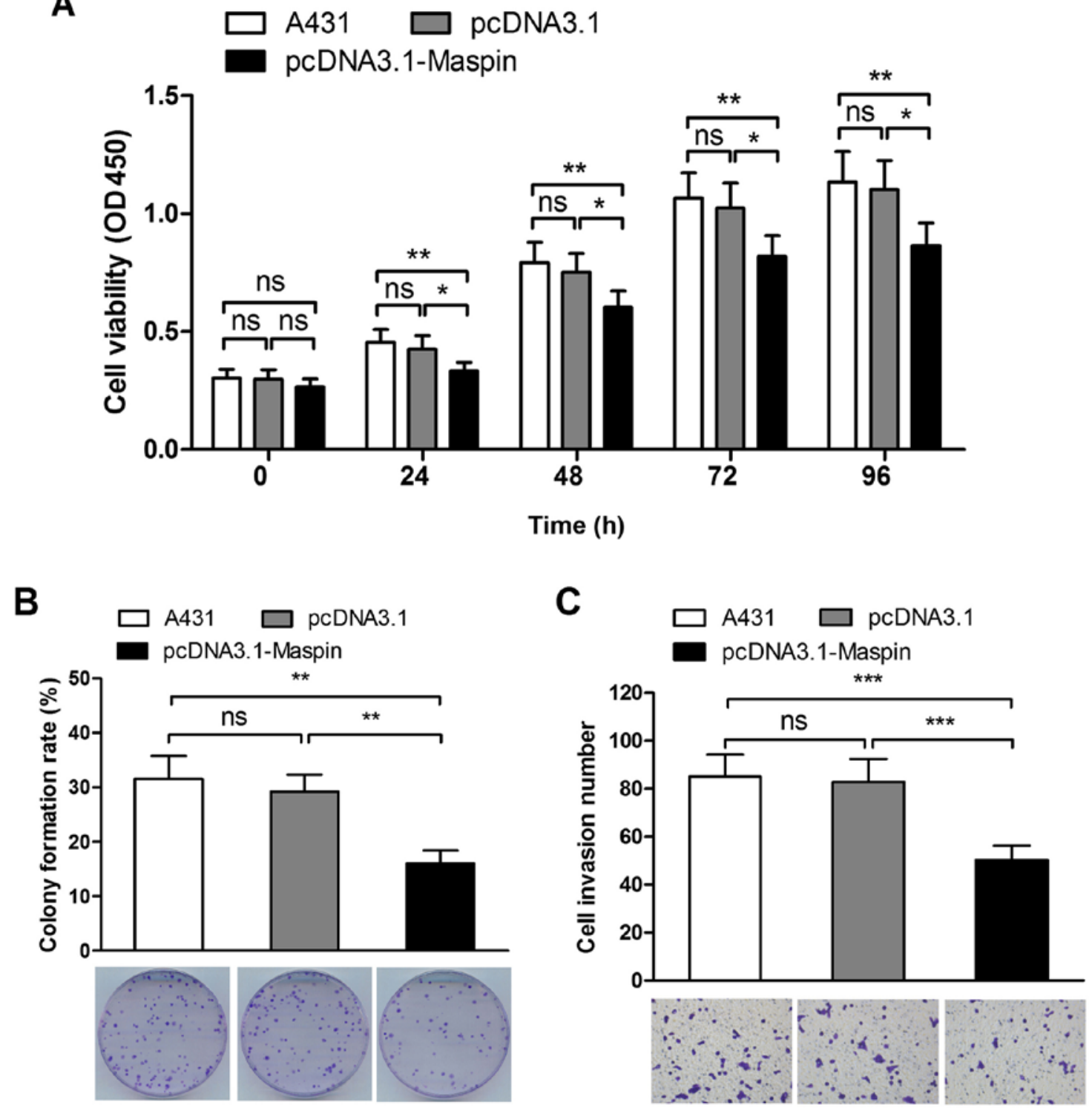

Figure 3. Maspin inhibits growth, proliferation and invasion in A431 cells. (A) Cell viability of A431 cells was detected by CCK-8 assay in different timepoints. (B) Colony formation ability of A431 cells was tested by plate colony formation assay. (C) Invasion potential of A431 cells was measured by Transwell assay in the presence of Matrigel in vitro $\left({ }^{*} \mathrm{P}<0.05,{ }^{* * *} \mathrm{P}<0.01,{ }^{* * *} \mathrm{P}<0.001\right.$; NS, not significant). 
A

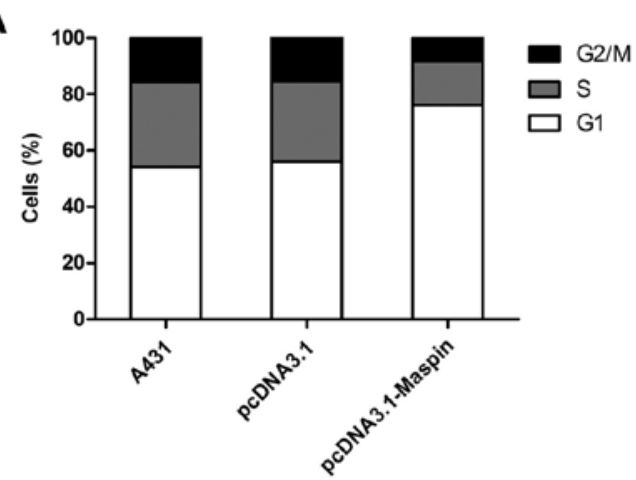

B

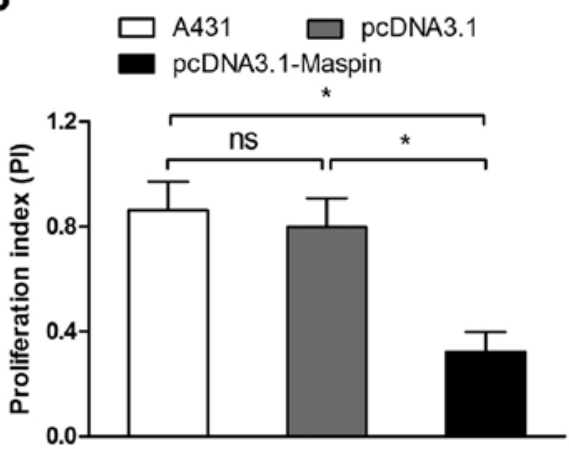

C
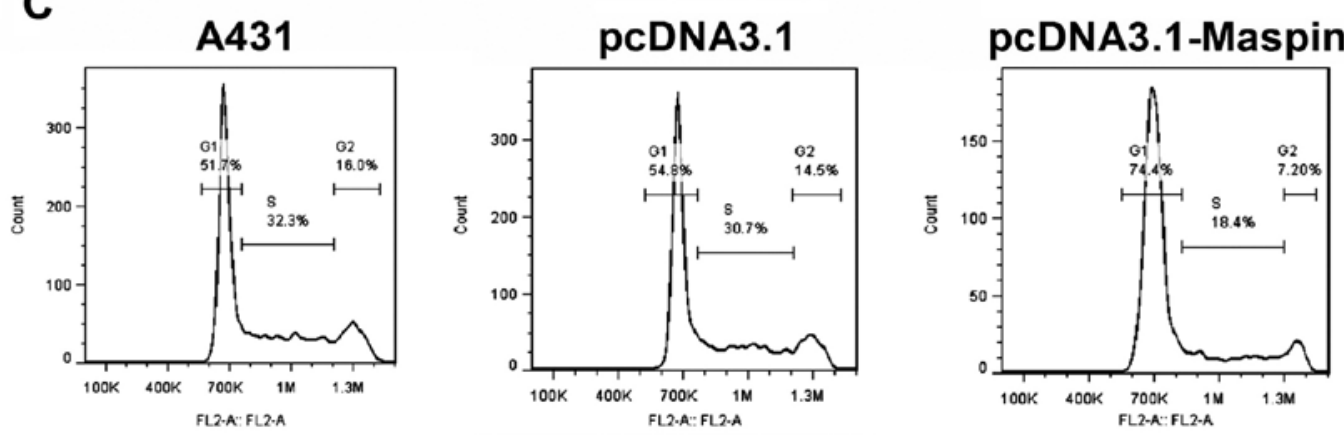

Figure 4. Maspin delayed cell cycle transition in A431 cells. (A) Distribution of A431 cells in three phases of cell cycle (G1 phase, S phase and G2/M phase) detected by flow cytometry. (B) Proliferation index (PI) of A431 cells in each group. PI = (percentage of cells in S phase $+\mathrm{G} 2 / \mathrm{M}$ phase) / percentage of cells in G1 phase. (C) Images of cell cycle detection of flow cytometry ("P<0.05; NS, not significant).

A
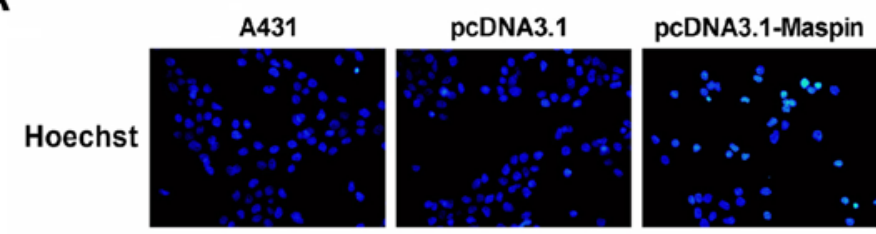

C
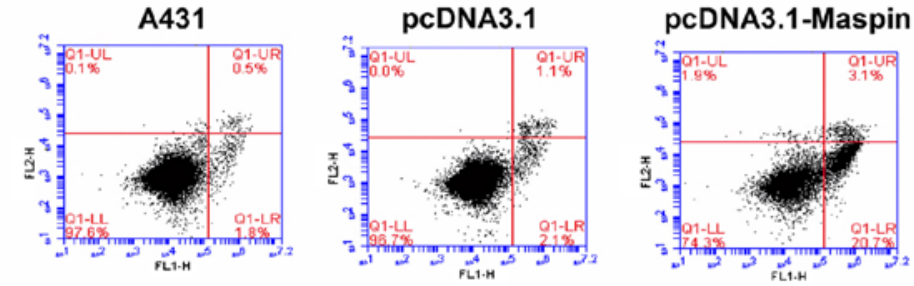

D

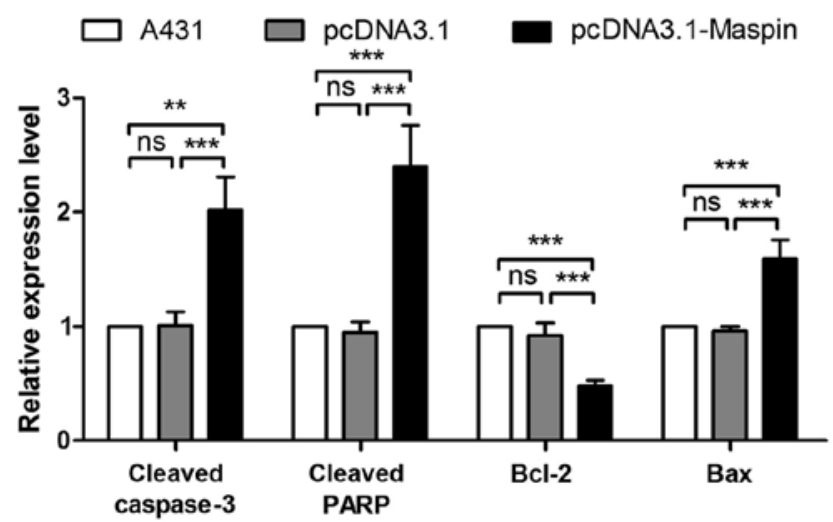

B

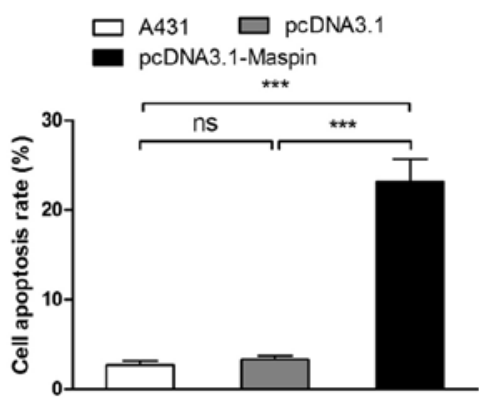

E

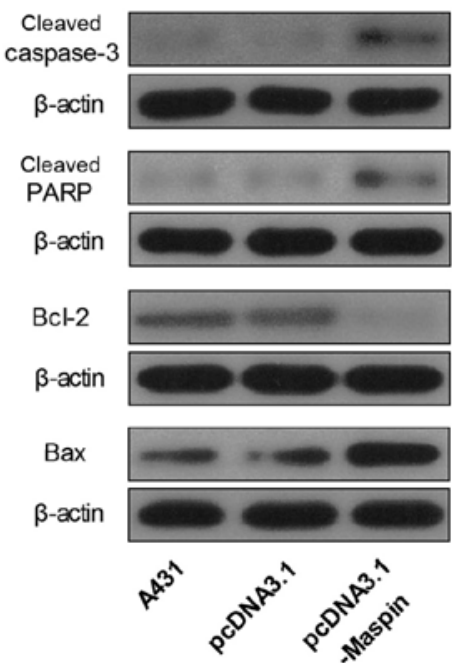

Figure 5. Maspin enhanced apoptosis in A431 cells. (A) Hoechst training was performed to detect apoptosis of A431 cells. (B) Apoptosis rate of A431 cells in each group was detected by flow cytometry. (C) Images of flow cytometry detection of apoptosis. (D and E) The expression levels of cleaved caspase-3, cleaved poly(ADP-ribose) polymerase (PARP), Bcl-2 and Bax assessed by western blotting $\left({ }^{* *} \mathrm{P}<0.01,{ }^{* * *} \mathrm{P}<0.001\right.$; NS, not significant). 
and E). These data suggested that Maspin enhanced apoptosis in A431 cells.

Collectively, Maspin was downregulated in cSCC tissues, and overexpression of Maspin inhibited growth, proliferation and invasion by delaying cell cycle transition and enhancing apoptosis in cSCC cells.

\section{Discussion}

With a metastatic rate of $5-10 \%(24,25)$, it is crucial for $\mathrm{cSCC}$ to be prevented and diagnosed in the early stage. Detection of clinical cSCC tissue samples showed that Maspin was significantly lowly expressed in cSCC tissues, suggesting that Maspin may be a practicable biomarker. Considering the infiltration and invasion, we chose the adjacent tissues $1 \mathrm{~cm}$ from cSCC tissue as the control to make the results more reliable.

Proliferation and metastasis of tumor cells are the crucial aspects of pathogenesis of malignant tumors. Our study demonstrated that Maspin overexpression inhibited cell growth, proliferation and invasion by delaying cell cycle transition and enhancing apoptosis in cSCC cells. Cells in different interphases could be distinguished by flow cytometry after staining with propidium iodide due to different amounts of DNA. By counting number of cells in different interphases and calculating the proliferation index (PI), we can determine the cell cycle process and compare the cell division speed among various groups. Apoptosis involves many aspects, detected by various methods. When apoptosis occurs, phosphatidylserine (PS) located in the inner cytomembrane moved to the external cytomembrane, which could be specially combined by Annexin V, thus early apoptosis could be discovered by testing PS using flow cytometry (26). With apoptosis further proceeding, and through staining, condensed chromatin, nuclear fragmentation and apoptotic bodies in apoptotic cells exhibited intense fluorescence under a fluorescence microscope (27).

In addition, apoptosis involves a variety of signaling pathways, expression change of genes in these signaling pathways would suggest the occurrence of apoptosis. Cysteinyl aspartate specific protease (caspase) is a protease family, including 11 members, with vital functions in apoptosis (28). Caspase family members are classified as initiators (caspase-1, -2, -4, $-5,-8,-9,-10,-11$ and -12 ) and executioners (caspase- $3,-6,-7$ and -14) (29). In normal cells, all caspase members are present as precursors without protease activity. When the extrinsic apoptotic signal enters the cell, the initiator (mainly caspase- 8 and -10) is self-cleaved and activated via allosteric cleavage and activates the executioner (mainly caspase-3) $(30,31)$. The cleaved caspase- 3 shears and activates PARP, causing apoptosis (32). On the other hand, executioner caspase also could be actived by intrinsic signals, such as DNA damage, growth factor deprivation and endoplasmic reticulum (ER) stress, which are regulated by members of B-cell lymphoma-2 (Bcl-2) family (33). Bcl-2 is one of the most important genes in apoptosis. Twenty-five homologous proteins have been found in Bcl-2 family to date, divided into two categories: anti-apoptotic proteins, including Bcl-2, Bcl-XL, Bcl-W, and Mcl-1; pro-apoptotic proteins, including Bax, Bak, Bim, and $\mathrm{Bad}$ (34). Pro-apoptotic protein receives intrinsic signals and induces downstream mediators (Bax and Bak), leading to the mitochondrial membrane permeability changes and the release of apoptogenic compound such as cytochrome $c$, which binds APAF-1 and activates caspase-9, further activating caspase-3 $(35,36)$. In this study, we demonstrated that Maspin participated in apoptosis signal pathway to enhance apoptosis, which was consistent with previous reports in other models $(17,18)$.

Since first reported in 1994 (14), Maspin has been studied widely, and its antitumor effect has been proved in many cell carcinoma and adenocarcinoma. Maspin suppresses cell proliferation, invasion and EMT, enhances apoptosis, repairs DNA damage (37), inhibits angiogenesis and elicits host antitumor immunity (19). During these processes, multiple genes play roles, including Bcl-2, Bax (17), p53, phosphatase and tensin homolog deleted on chromosome ten (PTEN) (38) and miRNA $(39,40)$, suggesting that Maspin participates in multiple signaling pathways. Since secreted by keratinocytes, Maspin is closely related to the function and fate of epidermal cells and keratinocytes (20). The role of Maspin in skin diseases has attracted increased attention. It has been reported that the survival rate of Maspin-positive $\mathrm{cSCC}$ patients is much higher than Maspin-negative patients (16), but the mechanism is unknown.

Our study found that Maspin was lower expressed in the clinical cSCC tissues than the adjacent normal tissues. We overexpressed Maspin in A431 cells, in which Maspin was downregulated, and demonstrated that the overexpression of Maspin inhibited cell growth, proliferation and invasion by suppressing cell cycle transition and enhancing apoptosis in cSCC cells. These findings may be of significance for the diagnosis and therapy of cSCC.

\section{References}

1. Lohmann CM and Solomon AR: Clinicopathologic variants of cutaneous squamous cell carcinoma. Adv Anat Pathol 8: 27-36, 2001.

2. Alam M and Ratner D: Cutaneous squamous-cell carcinoma. N Engl J Med 344: 975-983, 2001.

3. Bonerandi JJ, Beauvillain C, Caquant L, Chassagne JF, Chaussade V, Clavère P, Desouches C, Garnier F, Grolleau JL, Grossin M, et al; French Dermatology Recommendations Association (aRED): Guidelines for the diagnosis and treatment of cutaneous squamous cell carcinoma and precursor lesions. J Eur Acad Dermatol Venereol 25 (Suppl 5): 1-51, 2011.

4. Aboutalebi $S$ and Strickland FM: Immune protection, natural products, and skin cancer: Is there anything new under the sun? J Drugs Dermatol 5: 512-517, 2006.

5. Weinberg AS, Ogle CA and Shim EK: Metastatic cutaneous squamous cell carcinoma: An update. Dermatol Surg 33: 885-899, 2007.

6. Lippman SM, Parkinson DR, Itri LM, Weber RS, Schantz SP, Ota DM, Schusterman MA, Krakoff IH, Gutterman JU and Hong WK: 13-cis-retinoic acid and interferon alpha-2a: Effective combination therapy for advanced squamous cell carcinoma of the skin. J Natl Cancer Inst 84: 235-241, 1992.

7. Kwa RE, Campana K and Moy RL: Biology of cutaneous squamous cell carcinoma. J Am Acad Dermatol 26: 1-26, 1992.

8. Tanvetyanon T, Padhya T, McCaffrey J, Kish JA, Deconti RC, Trotti A and Rao NG: Postoperative concurrent chemotherapy and radiotherapy for high-risk cutaneous squamous cell carcinoma of the head and neck. Head Neck 37: 840-845, 2015.

9. Abd El-Maqsoud NM and Tawfiek ER: Loss of Maspin expression in bladder cancer: Its relationship with p53 and clinicopathological parameters. J Egypt Natl Canc Inst 22: 1-12, 2010.

10. Hopkins PC and Whisstock J: Function of maspin. Science 265: 1893-1894, 1994 
11. Pemberton PA, Wong DT, Gibson HL, Kiefer MC, Fitzpatrick PA, Sager R and Barr PJ: The tumor suppressor maspin does not undergo the stressed to relaxed transition or inhibit trypsin-like serine proteases. Evidence that maspin is not a protease inhibitory serpin. J Biol Chem 270: 15832-15837, 1995.

12. Al-Ayyoubi M, Gettins PG and Volz K: Crystal structure of human maspin, a serpin with antitumor properties: Reactive center loop of maspin is exposed but constrained. J Biol Chem 279: 55540-55544, 2004

13. Bodenstine TM, Seftor RE, Khalkhali-Ellis Z, Seftor EA, Pemberton PA and Hendrix MJ: Maspin: Molecular mechanisms and therapeutic implications. Cancer Metastasis Rev 31: 529-551, 2012.

14. Zou Z, Anisowicz A, Hendrix MJ, Thor A, Neveu M, Sheng S, Rafidi K, Seftor E and Sager R: Maspin, a serpin with tumorsuppressing activity in human mammary epithelial cells. Science 263: 526-529, 1994

15. Cai Z, Zhou Y, Lei T, Chiu JF and He QY: Mammary serine protease inhibitor inhibits epithelial growth factor-induced epithelial-mesenchymal transition of esophageal carcinoma cells. Cancer 115: 36-48, 2009

16. Wu S, Yu L, Cheng Z, Song W, Zhou L and Tao Y: Expression of maspin in non-small cell lung cancer and its relationship to vasculogenic mimicry. J Huazhong Univ Sci Technolog Med Sci 32: 346-352, 2012

17. Zhang W, Shi HY and Zhang M: Maspin overexpression modulates tumor cell apoptosis through the regulation of Bcl-2 family proteins. BMC Cancer 5: 50, 2005.

18. Li X, Chen D, Yin S, Meng Y, Yang H, Landis-Piwowar KR, Li Y, Sarkar FH, Reddy GP, Dou QP, et al: Maspin augments proteasome inhibitor-induced apoptosis in prostate cancer cells. J Cell Physiol 212: 298-306, 2007.

19. Dzinic SH, Chen K, Thakur A, Kaplun A, Bonfil RD, Li X, Liu J, Bernardo MM, Saliganan A, Back JB, et al: Maspin expression in prostate tumor elicits host anti-tumor immunity. Oncotarget 5: 11225-11236, 2014.

20. Reis-Filho JS, Torio B, Albergaria A and Schmitt FC: Maspin expression in normal skin and usual cutaneous carcinomas. Virchows Arch 441: 551-558, 2002.

21. Abdou AG, Maraee AH, El-Monaem Shoeib MA and Abo Saida AM: Maspin expression in epithelial skin tumours: An immunohistochemical study. J Cutan Aesthet Surg 4: 111-117, 2011.

22. Livak KJ and Schmittgen TD: Analysis of relative gene expression data using real-time quantitative PCR and the 2(-Delta Delta C(T)) method. Methods 25: 402-408, 2001.

23. Wang JH, Zhang L, Ma YW, Xiao J, Zhang Y, Liu M and Tang $\mathrm{H}$ : microRNA-34a-upregulated retinoic acid-inducible gene-I promotes apoptosis and delays cell cycle transition in cervical cancer cells. DNA Cell Biol 35: 267-279, 2016.

24. Cassarino DS, Derienzo DP and Barr RJ: Cutaneous squamous cell carcinoma: A comprehensive clinicopathologic classification. Part one. J Cutan Pathol 33: 191-206, 2006.
25. Cassarino DS, Derienzo DP and Barr RJ: Cutaneous squamous cell carcinoma: A comprehensive clinicopathologic classification - part two. J Cutan Pathol 33: 261-279, 2006.

26. Demchenko AP: The change of cellular membranes on apoptosis: Fluorescence detection. Exp Oncol 34: 263-268, 2012.

27. Bounda GA, Zhou W, Wang DD and Yu F: Rhein elicits in vitro cytotoxicity in primary human liver HL-7702 cells by inducing apoptosis through mitochondria-mediated pathway. Evid Based Complement Alternat Med 2015: 329831, 2015.

28. Nicholson DW and Thornberry NA: Caspases: Killer proteases. Trends Biochem Sci 22: 299-306, 1997.

29. Yi CH and Yuan J: The Jekyll and Hyde functions of caspases. Dev Cell 16: 21-34, 2009

30. Sarvothaman S, Undi RB, Pasupuleti SR, Gutti U and Gutti RK: Apoptosis: Role in myeloid cell development. Blood Res 50: 73-79, 2015.

31. Snigdha S, Smith ED, Prieto GA and Cotman CW: Caspase-3 activation as a bifurcation point between plasticity and cell death Neurosci Bull 28: 14-24, 2012.

32. Gerö D and Szabó C: Poly(ADP-ribose) polymerase: A new therapeutic target? Curr Opin Anaesthesiol 21: 111-121, 2008

33. Wei MC, Zong WX, Cheng EH, Lindsten T, Panoutsakopoulou V, Ross AJ, Roth KA, MacGregor GR, Thompson CB and Korsmeyer SJ: Proapoptotic BAX and BAK: A requisite gateway to mitochondrial dysfunction and death. Science 292: 727-730, 2001.

34. Besbes S, Mirshahi M, Pocard M and Billard C: New dimension in therapeutic targeting of BCL-2 family proteins. Oncotarget 6 : 12862-12871, 2015

35. Danial NN and Korsmeyer SJ: Cell death: Critical control points. Cell 116: 205-219, 2004

36. Nagata Y, Nagahisa H, Aida Y, Okutomi K, Nagasawa T and Todokoro K: Thrombopoietin induces megakaryocyte differentiation in hematopoietic progenitor FDC-P2 cells. J Biol Chem 270: 19673-19675, 1995 .

37. Zou Z, Gao C, Nagaich AK, Connell T, Saito S, Moul JW, Seth P, Appella E and Srivastava S: p53 regulates the expression of the tumor suppressor gene maspin. J Biol Chem 275: 6051-6054, 2000.

38. Eitel JA, Bijangi-Vishehsaraei K, Saadatzadeh MR, Bhavsar JR, Murphy MP, Pollok KE and Mayo LD: PTEN and p53 are required for hypoxia induced expression of maspin in glioblastoma cells. Cell Cycle 8: 896-901, 2009

39. Chen WS, Yen CJ, Chen YJ, Chen JY, Wang LY, Chiu SJ, Shih WL, Ho CY, Wei TT, Pan HL, et al: miRNA-7/21/107 contribute to $\mathrm{HBx}$-induced hepatocellular carcinoma progression through suppression of maspin. Oncotarget 6: 25962-25974, 2015.

40. Yuan K, Xie K, Fox J, Zeng H, Gao H, Huang C and Wu M: Decreased levels of miR-224 and the passenger strand of miR-221 increase MBD2, suppressing maspin and promoting colorectal tumor growth and metastasis in mice. Gastroenterology 145 853-864 e859, 2013 